\title{
Antimicrobial Activity of 1,3 Dihydroxy-2- Methylimidazolium Bis (Trifluoromethylsulfonyl) Imde and Selected Antibiotics Against Streptococcus Species Isolated from Groundwater in the Northwest Province, South Africa
}

\author{
Collins Njie Ateba ${ }^{1, *}$, Paul Katlego Morare ${ }^{1}$, Eno Ebenso ${ }^{2}$ \\ ${ }^{1}$ Department of Biological Sciences, School of Environmental and Health Sciences, Faculty of Agriculture, Science and Technology, \\ North West University- Mafikeng Campus, Private Bag X2046, Mmabatho 2735, South Africa \\ ${ }^{2}$ Department of Chemistry, School of Mathematical and Physical Sciences, Faculty of Agriculture, Science and Technology, North \\ West University - Mafikeng Campus, Private Bag X2046, Mmabatho 2735, South Africa \\ *Corresponding author: atebacollins1@hotmail.com
}

Received June 04, 2014; Revised August 28, 2014; Accepted September 10, 2014

\begin{abstract}
In developing countries, access to unsafe water and inadequate sanitation continue to be a danger to human health and untreated groundwater constitutes one of the main sources of drinking water supply. The consumption of untreated contaminated groundwater has frequently been identified as a potential source for the transfer and spread of both antibiotic resistant bacteria strains and waterborne infections among humans. Antibiotics are used for the treatment of bacterial infections and therefore the emergence of drug resistant bacterial strains has huge clinical implications. Faced with the rapid growth of bacterial resistance to a number of commonly used antibiotics, ionic liquids are attracting increasing attention as agents that could serve as antimicrobial agents. The aim of this study was to isolate, identify and determine the antimicrobial activity of an ionic liquid and selected antibiotics against Streptococcus species isolated from groundwater samples. A total of 22 samples were collected from borehole taps in some villages in the Northwest Province and analysed for the presence of streptococci. Gramstaining, catalase test, oxidase test and Prolex Streptococcal Grouping Latex assays were used for bacteria identification. The growth inhibitory effect of the ionic liquid 1,3 dihydroxy-2-methylimidazolium bis (trifluoromethylsulfonyl) imide and selected antibiotics was determined. One hundred and seventy six presumptive isolates were obtained and screened for characters of streptococci and 165 isolates were obtained. All the isolates were Gram positive cocci; a large proportion (92.7\%) was oxidase negative and only 51.5\% were catalase negative. Based on serotyping, $86.7 \%$ of the isolates were positively identified as streptococci. All the isolates from Motlhabeng, Stella and Taung were resistant to penicillin G. Moreover, large proportions (75.0\% to 95.8\%) of these isolates were resistant to vancomycin. All the isolates except a large proportion of those from Stella (88\%) and Taung (83\%) were found to be more susceptible (22.5\% to 50\%) to chloramphenicol. Generally, the growth inhibition zone diameter for 1,3 dihydroxy-2-methylimidazolium bis (trifluoromethylsulfonyl) imide against the isolates ranged from 6 to $9 \mathrm{~mm}$ and 9 to $22 \mathrm{~mm}$ for $1 \%$ and $10 \%$ solutions respectively. In conclusion multi-drug resistant streptococci were isolated from groundwater intended for human consumption. Isolates were however susceptible to the IL tested and the antimicrobial effect increased with increase in concentration of the IL.
\end{abstract}

Keywords: Streptococci, ionic liquids, 1,3 dihydroxy-2-methylimidazolium bis (trifluoromethylsulfonyl) imide, ionic liquids (ILs), antibiotics, multiple antibiotic resistance, multiple antibiotic resistance phenotypes

Cite This Article: Collins Njie Ateba, Paul Katlego Morare, and Eno Ebenso, “Antimicrobial Activity of 1,3 Dihydroxy-2-Methylimidazolium Bis (Trifluoromethylsulfonyl) Imde and Selected Antibiotics Against Streptococcus Species Isolated from Groundwater in the Northwest Province, South Africa." Journal of Food and Nutrition Research, vol. 2, no. 9 (2014): 627-632. doi: 10.12691/jfnr-2-9-16.

\section{Introduction}

Water is a vital natural resource because it is fundamental to life and the environment and is used in food production, industry and power generation [1]. Humans use water for drinking, cooking, recreation, transportation and irrigation [2]. Therefore, the quality of life depends largely on the physical, chemical and microbiological properties of the water to be utilized. Since contaminated water jeopardizes both the physical 
and social health to consumers, access to portable drinking water is a fundamental human need and therefore, a basic right of every individual [3]. Shortages of water, human activities and industrialization have been found to significantly affect the quality of water globally [4].

In developing countries untreated water and inadequate sanitation pose severe risks to human health [5]. Groundwater constitutes one of the main sources of drinking water supply in rural communities in most African countries [6]. These water sources are usually unprotected and this increases the opportunities for contamination with microbes of faecal origin such as Escherichia coli, Enterococcus species and Salmonella species [7]. Despite this, in South Africa, residents of most rural communities use untreated groundwater for drinking and household activities [8].

The consumption of untreated contaminated groundwater could serve as a potential source for the transfer and spread of water-borne infections and antibiotic resistant strains [9]. Consequently, the presence of antibiotic resistant isolates in groundwater in rural communities may have severe public health concerns on consumers. In addition, the consumption of contaminated groundwater has been reported to cause a large proportion of outbreaks of waterborne diseases worldwide $[7,8,10]$. These diseases pose a severe challenge to the medical profession if caused by multiple antibiotic resistant strains [7]. It is therefore beneficial for portable water to be free of microbial contamination thus, reducing the possibility of transmitting disease-causing microbes to consumers [3].

Streptococci and particularly Streptococcus pneumonia are a major cause of illnesses that include meningitis, bacteremia, community-acquired pneumonia and acute otitis in their hosts [11]. The treatment of these infections is usually achieved through the administration of antibiotics and therefore the emergence of drug resistant strains often complicates the management of these infections [12]. Antibiotic resistance is a situation in which some sub-populations of microorganisms, usually bacterial species are able to survive after exposure to one or more antibiotics. Resistance to three or more antibiosis is commonly termed multidrug resistance (MDR) [13]. Antibiotic resistance evolves naturally via natural selection through random mutation but it could also be engineered by applying an evolutionary stress on a population. Once an antibiotic gene has been generated in bacteria cells the genetic information can later be transferred to recipient cells in a horizontal fashion by plasmid exchange.

Faced with microbial resistance problems there is need to look for alternative agents that could have potential antimicrobial properties. Ionic liquids are basically salts that are in the liquid phase below $200^{\circ} \mathrm{C}$ [14]. Ionic liquids (ILs) are attracting increasing attention worldwide due to their unique properties, which include negligible vapor pressure, chemical and thermal stability, non-flammability, high ionic conductivity, low melting points, low viscosity, wide electrochemical potential window, solvation ability and antimicrobial activity $[15,16,17,18]$. ILs have been shown to exhibit antimicrobial activities against cocci, rods and fungi and there is usually a correlation between the structure of the cation and the antimicrobial activity of the solvent [19]. Due to their unique properties ILs are very useful in both the chemical and biological industries and also serve as successful replacements for some organic solvents used in synthetic [20,21] separation and extraction processes [22,23]. Given their environmental advantage and the fact that some ILs have been shown to possess antimicrobial activities $[15,16,17]$ we evaluated the effect of 1,3-dihydroxy-2-methylimidazolium bis (trifluoromethylsulfonyl) imide on streptococci isolated from groundwater. 1,3-dihydroxy-2-methylimidazolium bis (trifluoromethylsulfonyl) imide is an ionic liquid with a molecular weight of 409.28 and it is used as an $\mathrm{N}$ heterocyclic carbene (NHC) precatalyst. It is a solid at room temperature and melts at $72{ }^{\circ} \mathrm{C}$ [24]. The aim of this study was to isolate, identify and determine the toxicity of an ionic liquid and some selected antibiotics against Streptococcus species isolated from groundwater collected in some communities in the North West Province, South Africa.

\section{Materials and Methods}

\subsection{Sampling Site and Sample Collection}

A total of 22 samples were collected from borehole taps in some rural communities in the North West Province. These included 5 samples each from Ramosadi, Dibate and Motlhabeng and 1 from Stella, and 3 each from Vryburg and Taung. Water samples were collected aseptically, transported on ice to the laboratory for analysis.

\subsection{Analysis of Water Samples}

Water samples were analysed immediately upon arrival in the laboratory. Analysis was performed according to standard methods [25]. An aliquot of $100 \mathrm{~mL}$ from each sample was filtered using $0.45 \mu \mathrm{m}$ filter paper (Watman Glass Microfiber GS Filter paper) on a water pump machine (model Sartorius 16824). Membrane filters were transferred onto Brain Heart Infusion (BHI) agar plates and plates were incubated aerobically at $37^{\circ} \mathrm{C}$ for 24 to 48 hours. Typical white centred colonies were sub-cultured on BHI agar plates and plates incubated aerobically at $37^{\circ} \mathrm{C}$ for 24 to 48 hours. Eight presumptive Streptococcus isolates from each sample were randomly selected and their identities confirmed using primary and secondary identification tests.

\subsection{Bacterial Identification}

Presumptive isolates were identified using the following criteria:

\subsubsection{Cellular Morphology}

Presumptive isolates were Gram stained using standard methods [26].

\subsubsection{Preliminary Biochemical Identification Tests for Streptococci Species}

\subsubsection{Oxidase Test}

The oxidase test was performed using the oxidase test reagent from Pro-Lab Diagnostics- United Kingdom and performed as instructed by the manufacturer (Whatman International Ltd, Maidstone, England).

\subsubsection{Catalase Test}


The catalase test which is designed to detect the presence of the catalase enzymes in most aerobic and facultative anaerobic bacteria based on the presence of the cytochrome system was determined in all the isolates. Isolates from Gram positive and cocciod shaped cultures were reacted with $2 \%(\mathrm{v} / \mathrm{v})$ hydrogen peroxide on a clean microscope slide. The formation of bubbles was considered a positive result and vice versa.

\subsubsection{Confirmatory Biochemical Test for Streptococci}

\subsubsection{Serotyping}

A serological Prolix Streptococcal Grouping Latex agglutination kit obtained from PRO-LAB DiagnosticsUK was used to identify the isolates as streptococci based on the Lancefield grouping. The tests were performed by reacting cell wall specific carbohydrate extract of isolates with nitrous acid reagents as indicated by the manufacturer. A Streptococcus agalactiae $12386^{\mathrm{TM}}$ (ATCC 301754) and Staphylococcus strain (ATCC $^{\circledR}$ 43300) were reacted with the streptococcal positive control latex reagent provided by the manufacturer for quality control purposes.

\subsection{Antibiotic Susceptibility Testing}

Antibiotic susceptibility tests were performed on all Streptococcus isolates to determine their antibiotic resistant profiles using the Kirby-Bauer disc diffusion technique [27]. Before antibiotic sensitivity testing, the isolates were sub-culturing onto the $\mathrm{BHI}$ agar plates and incubated aerobically at $37^{\circ} \mathrm{C}$ for 24 hours. Bacterial suspensions of pure isolates were prepared and $100 \mu \mathrm{L}$ aliquots from these suspensions were spread-plated onto Mueller Hinton agar (Biolab, Merck, South Africa). The susceptibilities of the isolates against a panel of six different antibiotics obtained from Mast DiagnosticsUnited Kingdom were determined. The antibiotic discs were gently pressed onto the inoculated Mueller Hinton agar to ensure intimate contact with the surface and plates were incubated aerobically at $37^{\circ} \mathrm{C}$ for 24 hours [28]. The antibiotic inhibition zone diameters were measured and results obtained were used to classify isolates as being resistant, intermediate resistant or susceptible to a particular antibiotic based on standard reference values
[28]. Table 1 indicates the details of antibiotics used in the study.

Table 1. Details of antibiotics used in the study

\begin{tabular}{ccccc}
\hline Antibiotic & Disc conc. & $\mathrm{R}$ & $\mathrm{I}$ & $\mathrm{S}$ \\
\hline Ampicillin (AP) & $10 \mu \mathrm{g}$ & $\leq 11$ & $12-14$ & $\geq 15$ \\
Penicillin (PG) & $10 \mu \mathrm{g}$ & $\leq 20$ & $21-28$ & $\geq 29$ \\
Vancomycin (VA) & $30 \mu \mathrm{g}$ & $\leq 9$ & $10-11$ & $\geq 12$ \\
Tetracycline(T) & $30 \mu \mathrm{g}$ & $\leq 14$ & $15-18$ & $\geq 19$ \\
Chloramphenicol(C) & $30 \mu \mathrm{g}$ & $\leq 12$ & $13-17$ & $\geq 18$ \\
Erythromycin(E) & $15 \mu \mathrm{g}$ & $\leq 13$ & $14-22$ & $\geq 23$ \\
\hline
\end{tabular}

\subsection{Anti-Icrobial Activity of 1,3 Dihydroxy-2- Methylimidazolium (Trifluoromethylsulfonyl) Imide \\ Bis}

The toxicity of the 1,3 dihydroxy-2-methylimidazolium bis (trifluoromethylsulfonyl) imide on confirmed Streptococcus isolates was performed as previously described [29]. Solidified Muller Hinton agar was spreadplated with a dense suspension of the bacteria isolates. The inoculated agar was supplied with $6 \mathrm{~mm}$ diameter sterile paper discs that were soaked in two different concentrations (1\% and 10\%) (v/v) of the ionic liquid. Plates were incubated at $37^{\circ} \mathrm{C}$ for 24 hours and the diameters of the zones of growth inhibition around the discs were measured and reported in $\mathrm{mm}$.

\section{Results and Interpretation}

\subsection{Detection of Streptococci Using Biochemical Tests and Serological Assays}

A total of 22 groundwater samples were collected from borehole taps and analyzed for characters of streptococci. The number of isolates that satisfied both the preliminary (Gram staining, oxidase test and catalase test) and confirmatory identification test (serotyping) are shown in Table 2. A total of 165 presumptive isolates were screened for characters of streptococci and all the isolates were Gram positive cocci. When subjected to the oxidase test, large proportions $(92.7 \%)$ of these isolates were oxidase negative while $51.5 \%$ were catalase negative. Based on serological assay, $86.7 \%$ of the isolates were positively identified as Streptococcus species.

Table 2. Preliminary test results for the isolates obtained during the study

\begin{tabular}{ccccc}
\hline Sample station & GS (+ve coccus) & OT (-ve) & CT (-ve) & Serotyping (No. of isolates positively identified as streptococci) \\
\hline Ramosadi (NT=40) & 40 & 37 & 0 & 34 \\
Dibate (NT=40) & 40 & 31 & 0 & 38 \\
Motlhabeng (NT=29) & 29 & 29 & 29 & 29 \\
Stella (NT=8) & 8 & 8 & 8 & 5 \\
Vryburg (NT=24) & 24 & 24 & 24 & 20 \\
Taung (NT=24) & 24 & 24 & 24 & 17 \\
Total & 165 & 153 & 85 & 143 \\
\hline NT =Number tested; GS=Gram staining. OT=Oxidase test; CT= (Catalase test;
\end{tabular}

3.2. Percentage Antibiotic Resistance of Streptococci Species

All the Streptococci isolated were tested to determine their antibiotic susceptibility profiles to a panel of 6 different microbial agents and results obtained are shown in Table 3. All the isolates from Motlhabeng, Stella and Taung were resistant to penicillin G. Moreover, large proportions (75.0\% to $95.8 \%$ ) of these isolates were also resistant to vancomycin. In addition, large proportions
(75\% to 100\%) of the isolates from Taung, Motlhabeng, Dibate and Ramosadi were resistant to erythromycin (Table 3).

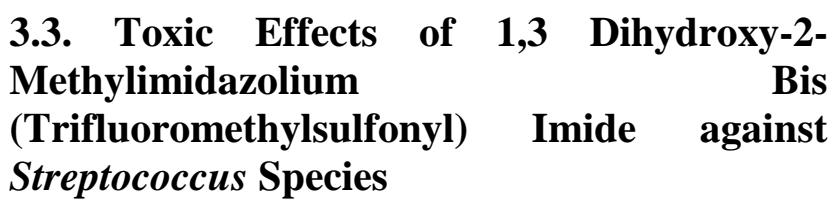


The growth inhibitory effect of the ionic liquid 1,3 dihydroxy-2-methylimidazolium bis (trifluoromethylsulfonyl) imide was determined. Generally, the growth inhibition zone diameter for the isolates ranged from 6 to $9 \mathrm{~mm}$ and 9 to $22 \mathrm{~mm}$ for $1 \%$ $(\mathrm{v} / \mathrm{v})$ and $10 \%(\mathrm{v} / \mathrm{v})$ solutions respectively of the ionic liquid.

Table 3. Antibiotic resistance data for streptococci obtained during the study

\begin{tabular}{cccccccc}
\hline $\begin{array}{c}\text { Sample } \\
\text { source }\end{array}$ & & AP & PG & VA & T & C & E \\
\hline $\begin{array}{c}\text { Ramosadi } \\
\text { (NT=40) }\end{array}$ & NR & 28 & 40 & 40 & 22 & 9 & 40 \\
$\%$ & $\%$ & 70 & 100 & 100 & 55 & 22.5 & 100 \\
$\begin{array}{c}\text { Dibate } \\
\text { (NT=40) }\end{array}$ & NR & 31 & 40 & 0 & 18 & 20 & 39 \\
$\%$ & $\%$ & 77.5 & 100 & 0 & 45 & 50 & 97.5 \\
Motlhabeng & $\mathrm{NR}$ & 21 & 28 & 21 & 22 & 8 & 25 \\
$(\mathrm{NT}=29)$ & $\%$ & 75 & 100 & 75 & 78.6 & 28.6 & 89.3 \\
$\%$ & $\mathrm{NR}$ & 7 & 8 & 6 & 8 & 7 & 1 \\
$\begin{array}{c}\text { Stella } \\
\text { (NT=8) }\end{array}$ & $\%$ & 88 & 100 & 75 & 100 & 88 & 13 \\
$\%$ & $\mathrm{NR}$ & 15 & 16 & 10 & 16 & 9 & 13 \\
Vryburg \\
$(\mathrm{NT}=24)$
\end{tabular}

NT= Number tested, NR = Number resistant, \% = Percentage resistant, $\mathrm{VA}=$ Vancomycin, $\mathrm{PG}=$ Penicillin, $\mathrm{AP}=$ Ampicillin, $\mathrm{E}=$ =Erythromycin, $\mathrm{C}=$ Chloramphenicol, $\mathrm{T}=$ Tetracycline

\section{Discussions}

Underground water is an aquatic biotope that harbours different types of micro-organisms [6]. The evolution and composition of the bacterial micro-flora depends on several factors such as the bacteria and solid particles mobility, the hydrodynamics and the hydrochemistry of the groundwater among others [10,30]. Groundwater constitutes one of the main sources of drinking water supply in most African cities [6]. The bacteriological quality of drinking water is responsible in the short-term for the immediate health risks on consumers and is therefore the most estimated property [31]. The distribution of bacterial species in aquatic environments in general and underground water in particular, is greatly influenced by environmental factors. Despite the fact that there is currently no data is available on the role of environmental factors on the bacterial community in groundwater in the study area, some studies have indicated the presence of microbial pathogens of faecal origin in groundwater intended for human consumption $[7,8]$. The present study was aimed at analyzing groundwater from some rural communities in the North West Province for the presence of faecal streptococci, a bacterial group of high medical importance especially in young children, elder and immune-compromised individuals.

Life depends on water and access to safe drinking water is essential [32]. In addition, access to portable drinking water is a fundamental human need and therefore a basic right of every individual, since contaminated water jeopardizes both the physical and social health to consumers [3]. In the present study, streptococci were successfully isolated from groundwater consumed by individuals in some rural communities in the North West Province, South Africa. The identities of these isolates were confirmed using Gram staining, oxidase test, catalase test and a serological assay. These same methods have been used for identification of Streptococcus species $[33,34,35]$. However, these tests are supplemented with molecular assays the isolates are identified at species level [35].

Another objective of this study was to determine the antibiotic resistance profiles of isolates obtained from water samples. The antibiotic resistance patterns of Streptococcus species from food products and humans have been investigated $[36,37,38,39]$. In the present study large proportions $(75.0 \%$ to $100 \%)$ of the isolates were most often resistant to penicillin $G$, vancomycin, and erythromycin. In the present study, isolates from different sample sites differed in their antimicrobial resistance patterns and similar observations have been reported [40]. In some of these studies resistance to tetracycline was the most common, followed by resistance to erythromycin, pirlimycin, and gentamicin [39]. Moreover, Streptococcus species have been reported to marked susceptibility to $\beta$ lactam antibiotics [37] and this is contrary to our finding. $S$. iniae isolates obtained from olive flounder (Paralichthys olivaceus) displayed susceptibility to cefotaxime, erythromycin, ofloxacin, penicillin, tetracycline and vancomycin when compared $S$. parauberis isolates that were highly resistant to erythromycin and tetracycline [38]. It is therefore suggested that the antibiotic resistance patterns of isolates within the same genus may differ despite the fact that they occupy the same ecological niche. This amplifies the need for constant testing and monitoring.

Antimicrobial resistance seems to be influenced by a number of factors that are unique to different areas and multi-drug resistance has become a primary issue of concern to physicians since it greatly affects therapeutic processes [41]. Therefore, as multi-drug resistant strains become increasingly prevalent, treatment options become limited [41]. Mortality associated with pneumococcal infections dropped dramatically following the advent of penicillin therapy [42]. However, drug-resistant strains, including those with reduced susceptibility to multiple antibiotics became increasingly prevalent in many parts of the world later on. The emergence of resistant strains greatly affected the options of antibiotics that may provide reliable and effective treatment of pneumococcal infections [11]. In the present study, all the isolates were found to be resistant to ampicillin (63\% to 100\%) and this may have resulted from the fact that the drug is frequently used in both veterinary and human medicine in the area. In addition isolates except those from Stella (88\%) and Taung (83\%) were highly susceptible to chloramphenicol. This may have resulted from the fact that chloramphenicol has been banned for inclusion as additives in feeds for animals [43]. Moreover, it is not used in veterinary medicine in the study area.

A further objective was to determine the effect of an ionic liquid, 1,3-dihydroxy-2-methylimidazolium bis (trifluoromethylsulfonyl) imide against streptococci isolated from groundwater samples. Generally, the ionic liquid had visible antimicrobial activity against the isolates and the degree of susceptibility depended greatly on the concentration of the liquid utilized. In the present 
study growth inhibition halo ranged from 6 to $9 \mathrm{~mm}$ and 9 to $22 \mathrm{~mm}$ for $1 \%$ and $10 \%$ solutions respectively. Similar to a previous report, the ability to induce apoptosis in Streptococcus cells dependent on the concentration of dispersions [44]. Room temperature ionic liquids have shown interesting chemical and biological properties and are effective against certain Gram-negative as well as Gram-positive bacteria [45]. They achieve these antimicrobial properties by affecting some proteins such as bovine serum albumin (BSA) and catalase (CAT) that are central to the survival of the cell [45]. In addition, several ionic liquids have been screened for antimicrobial activity activities, and results obtained were both interesting and promising [46]. To the best of our knowledge no study has been conducted in which 1,3 dihydroxy-2-methylimidazolium bis (trifluoromethylsulfonyl) imde was assayed to determine its antimicrobial activities. Despite this, two similar longchain imidazolium and pyridinium based ionic liquids namely 1-alkyl-3-methylimidazolium and 1alkylpyridinium bromides have been assessed against microorganisms to determine the contribution of the alkyl chain length and the nature of the cationic head group on the antimicrobial properties of the ionic liquids [47]. In the present study the imidazolium-based ionic liquid had negative effects on the growth of Streptococcus species isolated and similar observations have been reported for other imidazolium compounds [48]. However, in the previous study the inhibitory activity was highly dependent the type of anion present and the length of the alkyl chain.

\section{Conclusion}

In conclusion, the occurrence of multi-drug resistant isolates in developing countries is a course for concern as infections caused by these bacteria could have severe consequences on individuals. Their effects could even be amplified in rural communities where residents do not practice proper hygiene and have limited access to health care facilities. Proper water management practices and efforts to provide portable water to residents in rural communities cannot be overemphasized. This will limit the health implications on humans that result from consuming untreated ground water.

\section{Acknowledgement}

We gratefully acknowledge Mr. B.J Morapedi for his assistance during the collection of samples and Mrs Huyser Rika for technical assistance during this study. This study was financially supported by Department of Biological Sciences, North West University and the North West University Postgraduate Merit Bursary.

\section{References}

[1] Wose Kinge, C.N., Mbewe, M. and Sithebe, P.N., "Detection of Bacterial Pathogens in River Water Using Multiplex-PCR, Polymerase Chain Reaction”. Edited by Patricia HernandezRodriguez and Arlen Patricia Ramirez Gomez, InTech, Croatia (Ed.), ISBN: 978-953-51-0612-8.
[2] Wose Kinge, C. and Mbewe, M., "Characterisation of Shigella species isolated from river catchments in the North-West Province of South Africa”. SAJS 106 (11/12). 1-4. 2010.

[3] World Health Organization Emerging Issues in water and Infectious Diseases, World Health Organization, Geneva, Switzerland, 2003.

[4] Martellini, A., Payment, P. and Villemur, R., "Use of eukaryotic mitochondrial DNA to differentiate human, bovine, porcine and ovine sources in focally contaminated surface water". Water Res 39(4). 541-548. 2005,

[5] World Health Organization Evaluation of the costs and benefits of water and sanitation improvements at the global level. WHO/SDE/WSH/04.04, Geneva; 2004.

[6] Nola, M., Njine, T., Djuikom, E. and Foko, V.S., "Faecal coliforms and faecal streptococci community in the underground water in an equatorial area in Cameroon (Central Africa): the importance of some environmental chemical factors". Water Res 36. 3289-3297. 2002,

[7] Ateba, C.N. and Maribeng, M.D., "Detection of Enterococcus species in groundwater from some rural communities in the Mmabatho area, South Africa: A risk analysis”. Afr J Microbiol Res 5 (23). 3930-3935. 2011.

[8] Phokela, P.T., Ateba, C.N. and Kawadza, T.D., "Assessing antibiotic resistance profiles in Escherichia coli and Salmonella species from groundwater in the Mafikeng area, South Africa”. Afr J Microbiol Res 5 (32). 5902-5909. 2011.

[9] Sorum, H, and L'abee-Lund, T.M., “Antibiotic resistance in foodrelated bacteria-a result of interfering with the global web of bacterial genetics”. Int J Food Microbiol 78. 43-56. 2002.

[10] Camesano, T.A. and Logan, B.E., "Influence of fluid velocity and cell concentration on the transport of motile and non-motile bacteria in porous media”. Environ Sci Technol 32. 1699-708. 1998.

[11] Butler, J.C., Hoffmann, J., Cetron, M.S., Elliott, J.A., Fackiam, R.R. and Breiman, R.F., "The Continued Emergence of DrugResistant Streptococcus pneumonia in the United States. Int J Infect Dis 174. 986-93. 1996.

[12] Hofmann, J., Cetron, M.S., Farley, M.M., Baughman, W.S., Facklam. R.R., Elliott, J.A., Deaver, K.A. and Breiman, R.F., "The prevalence of drug-resistant Streptococcus pneumonia in Atlanta”. N Engl J Med 3 (8): 481-486. 1995.

[13] Levy, S.B., "Factors impacting on the problem of antibiotic resistance". J. Antimicrob Chemother 49 (1). 25-30. 2002.

[14] Weingartner, H., "Understanding Ionic Liquids at the Molecular Level: Facts, Problems and Controversies”. Angewandte Chemie Int Edn 47. 654-670. 2008.

[15] Pernak, J., Sobaszkiewicza, K. and Mirska, I., "Anti-microbial activities of ionic liquids". Green Chem 5. 52-56. 2003.

[16] Hough-Troutman, W.L., Smiglak, M., Griffin, S., Reichert, W.M., Mirska, I., Jodynis-Liebert, J., Adamska, T., Nawrot, J., Stasiewicz, M., Rodgers, R.D. and Pernak, J., "Ionic liquids with dual biological function: sweet and anti-microbial, hydrophobic quaternary ammonium-based salts”. N J Chem 33. 26-33. 2009.

[17] Busetti, A., Crawford, D.E., Earle, M.J., Gilea, M.A., Gilmore, B.F., Gorman, S.P., Laverty, G., Lowry, A.F., Mclaughlin, M. and Seddon, K.R., "Antimicrobial and antibiofilm activities of 1alkylquinolinium bromide ionic liquids”. Green Chem 12:.420425. 2010.

[18] Ventura, S.P.M., De Barros, R.L.F., Sintra, T., Soares, C.M.F., Lima, Á.S. and Coutinho, J.A.P., "Simple screening method to identify toxic/non-toxic ionic liquids: Agar diffusion test adaptation”. Ecotoxicol Environ Safety 83. 55-62. 2012.

[19] Hough, W.L. and Rogers, R.D., "Ionic liquids then and now: From solvents to materials to active pharmaceutical ingredients". Bull Chem Soc Jap 80. 2262-2269. 2007.

[20] Seddon, K.R.J., "Ionic Liquids for Clean Technology". J Chem Technol Biotech 68. 351-356. 1997,

[21] Gordon, C.M., "New developments in catalysis using ionic liquids”. Appl Cat A-Gen 222 (1-2). 101-117. 2001,

[22] Visser, A.E., Swatloski, R.P., Griffin, S.T., Hartman, D.H. and Rodgers, R.D., "Liquid/liquid extraction of metal ions in room temperature ionic liquids". Separation Sci Technol 36. 785. 2001.

[23] Visser, A.E., Swatloski, R.P., Griffin, S.T., Hartman, D.H. and Rodgers, R.D., Room Temperature Ionic Liquids as Replacements for Traditional Organic Solvents and their applications towards "Green Chemistry" in Separation Processes. NATO Sci Series 92. 137-156. 2002. 
[24] Laus G, et al., "N,N-Di (alkoxy) imidazolium salts: new patentfree ionic liquids and NHC-precatalysts". Naturforsch B62. 295308. 2007.

[25] APHA. Standard methods for the examination of Water and Wastewater, 19th edition American Public Health Association, Washington DC; 1998.

[26] Cruikshank, R., Duguid, J.P., Marmoin, B.P. and Swain, R.H., Medical Microbiology Volume 2. 12th edition. New York: Longman Group Limited; 1975: 34

[27] Kirby, W.M.M., Bauer, A.W., Sherris, J.C. and Turck, M "Antibiotic susceptibility testing by single disc method". Am J Clin Pathol 45: 4. 1996.

[28] National Committee for Clinical Laboratory Standards Methods for dilution antimicrobial susceptibility test for bacteria that grow aerobically. 4th edition. M7-A4. Villanova, PA; 1999.

[29] Hossain, I.M., El-Harbawi, M., Noaman, Y.A., Bustam, M.A.B., Alitheen, N.B.M., Affandi, N.A., Hefter, G. and Yin, C. "Synthesis and anti-microbial activity of hydroxylammonium ionic liquids”. Chemosphere 84. 101-105. 2011.

[30] Banton, O. and Bangoy, L.M., Hydrogeology, underground waters environmental multiscience. Puq/Aupelf edition, Sainte-Foy, pp 460; 1997.

[31] Kreissel, W., "Water quality and health”. Water Sci Technol 23. 201-209. 1991.

[32] Meays, C., Broersma, K., Nordin, R. and Mazumder, A., "Source tracking faecal bacteria critical review of current methods". $J$ Environ Manag 73. 71-79. 2004.

[33] Amoroso, P., de Ávila Célia, F.A., Gagliardi, M.O., "Prevalence of Streptococcus in saliva of children and adolescents". Braz J Oral Sci. 2(4). 164-168. 2003.

[34] Wyder, A.B., Boss, R., Naskova, J., Kaufmann, T., Steiner, A., Graber, H.U., Streptococcus spp. and related bacteria: their identification and their pathogenic potential for chronic mastitis-a molecular approach. Res Vet Sci 91. 349-357. 2011

[35] Raemy1, A., Meylan, M., Casati, S., Gaia, V., Berchtold, B., Boss, R., Wyder, A., Graber, H.U., "Phenotypic and genotypic identification of streptococci and related bacteria isolated from bovine intramammary infections”. Acta Veterinaria Scandinavica 55. 53. 2013

[36] Westlinga, K., Julandera, I., Ljungmanb, P., Jalalc, S., Nordc, C.E., Wretlind, B., "Viridans group streptococci in blood culture isolates in a Swedish university hospital: antibiotic susceptibility and identification of erythromycin resistance genes". Int $J$ Antimicrob Agents 28 (4). 292-296. 2006.

[37] Pitkälä, A., Koort, J., Björkroth, J., “Identification and Antimicrobial Resistance of Streptococcus uberis and
Streptococcus parauberis Isolated from Bovine Milk Samples”. $J$ Dairy Sci 91 (10), 4075-4081. 2008.

[38] Parka, Y., Nhoa, S., Shinb, G., Parka, S., Janga, H., Chaa, I., Haa, M., Kima, Y., Dalvia, R.S., Kangc, B., Junga, T., "Antibiotic susceptibility and resistance of Streptococcus iniae and Streptococcus parauberis isolated from olive flounder (Paralichthys olivaceus)”. Vet Microbiol 136 (1-2), 76-81. 2009.

[39] Minst, K. Märtlbauer, E., Miller, T., Meyer, C., "Streptococcus species isolated from mastitis milk samples in Germany and their resistance to antimicrobial agents”. J Dairy Sci 95 (12). 6957-6962. 2012.

[40] Harakeh, S., Yassinea, H. and Mutasem, E., "Antimicrobialresistance of Streptococcus pneumonia isolated from the Lebanese environment”. Marine Environ Res 62 (3). 181-193. 2006.

[41] Daka, D., Loha, E. and Giday, A., "Streptococcus pneumonia and antimicrobial resistance, Hawassa Referral Hospital, South Ethiopia”. J Med Lab Diag 2 (3). 27-30. 2011.

[42] Austrian, R., "Confronting drug-resistant pneumococci". Annals Int Med 121. 807-809. 1994.

[43] Bischoff, K.M., White, D.G., McDermott, P.F., Zhao, S., Gaines, S., Maurer, J.J. and Nisbet, D.J., "Characterization of chloramphenicol resistance in beta-haemolytic Escherichia coli associated with diarrhoea in neonatal swine”. J Clin Microbiol 40 (2). 389-394. 2002.

[44] Saadeh, M., Yasseen, Z., Sharif, F.A., Hazem, M. and Shawish, A. "New room temperature ionic liquids with interesting ecotoxicological and antimicrobial properties". Ecotoxicol Environ Safety 72. 1805-1809. 2009.

[45] Messali, M., Moussa, Z., Alzahrani, A.Y., El-Naggar, M.Y., Eldouhaibi, A.S., Judeh, Z.M.A. and Hammouti, B., "Synthesis, characterization and the antimicrobial activity of new eco-friendly ionic liquids”. Chemosphere 91 (11). 1627-1634. 2013.

[46] Cornellas, A., Perez, L., Cornellas, F., Ribosa, I., Manresa, A. and Garcia, M.T., "Self-aggregation and antimicrobial activity of imidazolium and pyridinium based New room temperature ionic liquids in aqueous solution. J. Colloid Interface Sci 355 (1). 164171. 2011.

[47] Ventura, S.P.M., Marques, C.S., Rosatella, A.A., Afonso, C.A.M., Gonçalves, F. and Coutinho, J.A.P., "Toxicity assessment of various ionic liquid families towards Vibrio fischeri marine bacteria”. Ecotoxicol Environ Safety 76. 162-168. 2012.

[48] Liang, C., Ho, W., Yeh, L., Cheng, Y. and Chou, T., "Effects of 1hexadecyl-3-methylimidazolium ionic liquids on the physicochemical characteristics and cytotoxicity of phosphatidylcholine vesicles”. Colloids Surfaces A: Physicochem Engineering Aspects 436. 1083-1091. 2013. 